\title{
Abiraterone plus prednisone improves survival in metastatic castration-resistant prostate cancer
}

\author{
Scott T Tagawa and Himisha Beltran \\ Asian Journal of Andrology (2011) 13, 785-786; doi:10.1038/aja.2011.113; Published online: 22 August 2011
}

I n essentially just 1 year's time, we have seen science translated into exciting new therapeutic agents for men with metastatic castration-resistant prostate cancer (CRPC), ${ }^{1}$ most recently with the United States Food and Drug Administration (FDA) approval of abiraterone acetate in combination with prednisone. ${ }^{2}$ While prostate cancer has been known to be highly responsive to surgical or medical castration for well over half a century, ${ }^{3}$ what was once termed 'hormone refractory' prostate cancer inevitably developed, leading to cancerrelated death. Many consider the introduction of chemotherapy for CRPC initially for symptomatic benefit, then with improvements in survival, a substantial step forward. Nonetheless, most patients experience disease progression within months. Multiple factors, including unfavorable perceptions of benefit/ toxicity ratio, therapeutic nihilism, barriers to shift in care between medical disciplines, a low percentage of patients participating in clinical trials and several 'negative' studies, left the field at a therapeutic standstill since 2004 .

It is now widely recognized that despite castrate levels of serum testosterone, most prostate tumors remain dependent on androgen receptor (AR) signaling, which can occur through AR gene amplification, activating mutations, AR promiscuity, intratumoral ligand (e.g., testosterone) production, AR bypass pathways or alternative mechanisms. ${ }^{4,5}$ Drugs such as ketoconazole, which inhibit production of adrenal precursors into testosterone ( $\mathrm{T}$ ) and dihydrotestosterone, may have clinical benefit in some patients with CRPC, but no clinical study had shown a survival benefit associated with secondary hormonal manipulations. More recently,

Departments of Medicine and Urology, Weill Cornell Medical College, Weill Cornell Cancer Center, New York, NY 10065, USA

Correspondence: Dr ST Tagawa (stt2007@

med.cornell.edu) intratumoral conversion of adrenal precursors into $\mathrm{T}$ and dihydrotestosterone has been identified in CRPC. ${ }^{6,7}$

Abiraterone acetate is a potent inhibitor of cytochrome P450 c17 ( $17 \alpha$-hydroxylase/ C17,20 lyase), which inhibits conversion of androgen precursors to $\mathrm{T}$ and dihydrotestosterone in testes, adrenal glands and prostate tumor tissue, and is more potent and selective than ketoconazole. ${ }^{8,9}$ Phase I and II trials demonstrated relative safety and efficacy, leading to randomized, placebo-controlled phase III trials. ${ }^{9}$ In the recently reported trial, 1195 men with progressive metastatic CRPC who previously received docetaxel-based chemotherapy were randomized in a $2: 1$ fashion to abiraterone acetate plus prednisone versus placebo plus prednisone with the primary end point of overall survival. A preplanned interim analysis demonstrated a statistically significant and clinically meaningful improvement in overall survival from a median of 10.9-14.8 months (hazard ratio: 0.65; 95\% confidence interval: $0.54-0.77$ ), and the independent data safety monitoring board recommended release of results and unblinding of the data; subjects who received placebo were offered crossover to active drug. In addition to overall survival improvement, benefit in progression-free survival (as measured by prostate-specific antigen as well as radiographic evidence) and response rates were seen. All subgroups analyzed experienced a benefit. Further analysis demonstrated symptomatic benefit in terms of pain control and skeletal-related events. ${ }^{10}$

In general, abiraterone acetate is well tolerated. In the phase III study including prednisone, toxicities related to mineralocorticoid excess including hypokalemia, fluid retention, and hypertension were seen as expected based upon the mechanism of action. Most toxicities were low grade, with all grade 3 and 4 toxicities occurring in less than $10 \%$ of patients. Modest doses of corticosteroids can in part overcome the mineralocorticoid excess seen with feedback stimulation of adrenocorticotropic hormone with relative decreases in serum cortisol as the result of $17 \alpha$-hydroxylase inhibition. As single-armed studies have been performed without the addition of corticosteroids, some have advocated the omission of routine corticosteroids, instead adding them on progression, often with the use of the mineralocorticoid antagonist eplerenone to decrease toxicity. ${ }^{11}$ Though there may be rationale, particularly should abiraterone be used at an earlier stage of disease (presumably for longer periods of time), this is in the absence of randomized data, the FDA has approved abiraterone acetate in combination with prednisone, and eplerenone is not widely available in the United States. It should be noted that spironolactone should not be substituted. In addition to the above, the practicing physician needs to be aware of significant variability in abiraterone's absorption with food (particularly fatty food) and potential drug-drug interactions.

The current FDA approval is abiraterone acetate and prednisone for men with metastatic CRPC who have previously received docetaxel. As commented upon in the accompanying editorial, should this be the case with the currently available evidence ${ }^{12}$ We as clinical investigators in conjunction with the FDA created artificial 'boxes' based less upon biology than on convenience. While the previous quickest pathway to FDA approval was in the refractory to initial hormonal therapy and chemotherapy setting, and because of logistics or industry fears of testing new therapies head to head with docetaxel, does it make sense to deprive patients of off-label use of approved therapies that have demonstrated some level of safety and efficacy? While the placebo-controlled randomized study of abiraterone acetate in the 'minimally 
symptomatic', pre-chemotherapy state has been completed, future studies will likely need to either examine combinations where a placebo component may be ethical (i.e., approved drug A+experimental drug B vs. drug A+placebo), use a standard, active therapy as a control or test new drugs versus placebo or best supportive care in the post-sipuleucel $\mathrm{T}$, docetaxel, abiraterone and cabazitaxel space.

Clinical biomarkers to evaluate response to therapies for CRPC is an area of active research, especially in this new abiraterone era. Potent hormonal agents are expected to decrease transcription of androgen regulated genes (such as prostate-specific antigen), such that declines in serum prostate-specific antigen may be seen even in the absence of cell killing. Therefore, we are in need of alternative or complementary biomarkers. Circulating tumor cells (CTCs) are a leading candidate. ${ }^{13}$ COU-AA-301 was the first randomized phase III trial to report prospectively assessed CTC count as measured by EpCAM-based immunomagnetic capture (CellSearch; Veridex, Raritan, NJ, USA) as a prognostic marker, confirming that baseline circulating tumor cell count and other biochemical markers such as LDH were key predictors of survival; work on a prognostic and potentially predictive surrogate biomarker model is ongoing. ${ }^{14}$ These important findings have led to re-evaluation of biomarker panels for CRPC and prospective evaluation of CTCs in the context of other therapies, with molecular profiling of CTCs as a 'liquid biopsy' particularly intriguing. Additional imaging biomarkers are also of interest based upon the limitations of current clinically available scans, and some are particularly attractive for AR-based therapies. ${ }^{15}$

With the FDA approval of abiraterone acetate and several other new potent hormonal therapies on the horizon, new questions are arising as to how they should be incorporated into the management of patients. What are the long-term effects of further suppressing the androgen axis (e.g., cardiovascular effects, sarcopenia and osteoporosis)? Is continued testicular suppression with luteinizing hormone releasing hormone agonist/antagonist therapy necessary? Should abiraterone be combined with other AR-targeted therapies, such as androgen receptor inhibitors or with other agents which may act on the AR pathway (including docetaxel)? ${ }^{16}$ How will this subsequently change the natural history of disease? One must recognize that variants of prostate cancer do exist which do not express AR and biologically act and respond differently. ${ }^{17}$ It is possible that by increasing pressure antagonizing the AR pathway that we will select for this aggressive anaplastic or neuroendocrine phenotype or neuroendocrine phenotype which is not expected to respond to hormonal therapy. ${ }^{18}$

This is an exciting time for genitourinary oncologists, with a relatively recent 'embarrassment of riches' in advanced renal cell carcinoma. ${ }^{19}$ It is high time that a variety of new options are available to improve morbidity and mortality in metastatic CRPC. ${ }^{1,2}$ A better understanding of tumor biology, development and validation of new molecular and clinical biomarkers, and incorporation of science into the rational development of new therapeutic strategies and trial end points for CRPC promises to improve the way we manage patients with CRPC. We must not be complacent and should continue to translate science into therapeutic reality for our patients.

1 Beltran H, Beer TM, Carducci MA, de Bono J, Gleave M et al. New therapies for castration-resistant prostate cancer: efficacy and safety. Eur Urol 2011; 60: 27990.

2 de Bono JS, Logothetis CJ, Molina A, Fizazi K, North S et al. Abiraterone and increased survival in metastatic prostate cancer. N Engl J Med 2011; 364: 19952005.

3 Huggins C, Hodges CV. The effect of castration, of estrogen and of androgen injection on serum phosphatases in metastatic carcinoma of the prostate. Cancer Res 1941; 1: 239-97.

4 Scher HI, Sawyers CL. Biology of progressive, castration-resistant prostate cancer: directed therapies targeting the androgen-receptor signaling axis. J Clin Oncol 2005; 23: 8253-61.

5 Massard C, Fizazi K. Targeting continued androgen receptor signaling in prostate cancer. Clin Cancer Res 2011; 17: 3876-83.

6 Montgomery RB, Mostaghel EA, Vessella R, Hess DL, Kalhorn TF et al. Maintenance of intratumoral androgens in metastatic prostate cancer: a mechanism for castration-resistant tumor growth. Cancer Res 2008; 68: 4447-54.

7 Locke JA, Guns ES, Lubik AA, Adomat HH, Hendy SC et al. Androgen levels increase by intratumoral de novo steroidogenesis during progression of castrationresistant prostate cancer. Cancer Res 2008; 68 : 6407-15.

8 Rowlands MG, Barrie SE, Chan F, Houghton J, Jarman $\mathrm{M}$ et al. Esters of 3-pyridylacetic acid that combine potent inhibition of 17 alpha-hydroxylase/ C17,20-lyase (cytochrome P45017 alpha) with resistance to esterase hydrolysis. J Med Chem 1995; 38: 4191-7.

9 Attard G, Reid AH, Yap TA, Raynaud F, Dowsett M et al. Phase I clinical trial of a selective inhibitor of CYP17, abiraterone acetate, confirms that castration-resistant prostate cancer commonly remains hormone driven. J Clin Oncol 2008; 26: 4563-71.

10 Logothetis C, de Bono JS, Molina A, Basch EM, Fizazi $\mathrm{K}$ et al. Effect of abiraterone acetate (AA) on pain control and skeletal-related events (SRE) in patients (pts) with metastatic castration-resistant prostate cancer (mCRPC) post docetaxel (D): results from the COU-AA-301 phase III studyJ Clin Oncol 2011; 29(Suppl): abstr 4520.

11 Attard G, Reid AH, de Bono JS. Abiraterone acetate is well tolerated without concomitant use of corticosteroids. J Clin Oncol 2010; 28: e560-1; author reply e562.

12 Antonarakis ES, Eisenberger MA. Expanding treatment options for metastatic prostate cancer. N Engl J Med 2011; 364: 2055-8.

13 de Bono JS, Scher HI, Montgomery RB, Parker C, Miller MC et al. Circulating tumor cells predict survival benefit from treatment in metastatic castration-resistant prostate cancer. Clin Cancer Res 2008; 14: 6302-9.

14 Scher HI, Heller G, Molina A, Kheoh TS, Attard G et al. Evaluation of circulating tumor cell (CTC) enumeration as an efficacy response biomarker of overall survival (OS) in metastatic castrationresistant prostate cancer (mCRPC): planned final analysis (FA) of COU-AA-301, a randomized doubleblind, placebo-controlled phase III study of abiraterone acetate $(A A)$ plus low-dose prednisone $(P)$ post docetaxel. J Clin Oncol 2011; 29 (Suppl): abstr LBA4517.

15 Evans M, Smith-Jones PM, Wongvipat J, Navarro V, Kim S et al. Noninvasive measurement of androgen receptor signaling with a positron-emitting radiopharmaceutical that targets prostate-specific membrane antigen. Proc Natl Acad Sci USA 2011; 108 : 9578-82.

16 Zhu ML, Horbinski CM, Garzotto M, Qian DZ, Beer $\mathrm{TM}$ et al. Tubulin-targeting chemotherapy impairs androgen receptor activity in prostate cancer. Cancer Res 2010; 70: 7992-8002.

17 Tagawa ST, Hamid O, Skinner E, Kumar P. Uncommon cancers of the prostate. In: Raghavan D, Brecher ML, Johnson DH, Meropol NJ, Moots PL, Rose PG, editors. Textbook of Uncommon Cancer. 3rd ed. West SussexWiley \& Sons, Ltd; 2006; 38-65.

18 Hirano D, Okada Y, Minei S, Takimoto Y, Nemoto N. Neuroendocrine differentiation in hormone refractory prostate cancer following androgen deprivation therapy. Eur Urol 2004; 45: 586-92.

19 Vogelzang NJ. Treatment Options in Metastatic Renal Carcinoma: An Embarrassment of Riches. New York: Grune Stratton; 2006. p1. 